\title{
Vertebroplasty in Osteoporotic Spine Fractures: A Quality of Life Assessment
}

\author{
Krishna Kumar, A.K. Verma, Jefferson Wilson, Alika LaFontaine
}

\begin{abstract}
Objective: Our goal was to perform a quantitative evaluation of the improvement in functional capacity, quality of life, mental function, reduction in drug intake and impact on hospital admissions after vertebroplasty in the treatment of osteoporotic compression fractures. The efficacy of vertebroplasty in relief of pain has been addressed in previous publications but the quantitative evaluation of improvement in quality of life has not been addressed before. Methods: This is a prospective study of 42 patients with 83 symptomatic vertebral fractures treated by vertebroplasty with a mean follow-up of 9.1 months. The outcome was measured by pre and postoperatively utilizing the Visual Analogue Scale, the Oswestry Disability Index, the Rolland Morris Scale for Back Pain and EuroQol-5D questionnaire (EQ-5D). The postoperative evaluations were performed at one week, one month, three month, and six month intervals thereafter. Results: In 34 out of 39 active patients, marked pain relief was noted (87\%). The Visual Analogue Scale score improved from a mean preoperative score of 8.2 to a mean postoperative score of $2.9(\mathrm{p}=0.0000003)$ at one week follow up and 3.9 at the last follow-up. The Rolland Morris Scale for Back Pain showed a drop from a mean preoperative rating of 13 to a mean postoperative rating of 10 , showing a $25 \%$ improvement $(\mathrm{p}=0.0207)$. The Oswestry Disability Index preoperatively was 64.4 which improved to 43.8 postoperatively, showing a $32 \%$ improvement $(\mathrm{p}=0.0207)$. The EQ-5D showed a mean preoperative index value of 0.097 and mean postoperative index value of $0.592(\mathrm{p}=0.0000003)$. All p-values were determined by the Willcoxin sign-ranked test. Conclusion: Vertebroplasty is a safe and efficacious procedure with a resulting improvement in pain and quality of life.
\end{abstract}

RÉSUMÉ: La vertébroplastie dans les fractures ostéoporotiques de la colonne vertébrale: évaluation de la qualité de vie. Objectif: Le but de cette étude était d'évaluer quantitativement l'amélioration fonctionnelle, la qualité de vie, la fonction mentale, la diminution de la prise de médicaments et l'impact sur l'hospitalisation chez les patients ayant subi une vertébroplastie pour traiter des fractures ostéoporotiques par compression. L'efficacité de la vertébroplastie pour le soulagement de la douleur a fait l'objet de publications antérieures, mais l'évaluation quantitative de l'amélioration de la qualité de vie n'a pas été étudiée. Méthodes: Il s'agit d'une étude prospective de 42 patients présentant 83 fractures vertébrales symptomatiques traitées par vertébroplastie. Le suivi moyen a été de 9,1 mois. Le résultat était évalué au moyen de l'échelle analogue visuelle (ÉAV), du questionnaire d'invalidité d'Oswestry (QIO), de l'échelle de Rolland-Morris (ÉRM) pour l'évaluation de la douleur et de l'échelle EQ-5D avant et après la chirurgie. Les évaluations postopératoires étaient effectuées après 1 semaine, 1 mois, 3 mois et aux 6 mois par la suite. Résultats: Chez 34 des 39 patients actifs, une diminution importante de la douleur a été notée (87\%). Le score à l'ÉAV s'est amélioré, passant d'un score moyen avant la chirurgie de 8,2 à un score moyen après la chirurgie de $2,9(\mathrm{p}=0,0000003)$ à 1 semaine et à 3,9 au moment de la dernière évaluation du suivi. Le score à l'ÉRM a baissé, la moyenne étant de 13 avant la chirurgie et de 10 après, soit une amélioration de 25\% ( $p=0,0207$ ). Le score au QIO était de 64,4 avant la chirurgie et de 43,8 après, soit une amélioration de $32 \%(p=0,0207)$. Le score moyen au questionnaire EQ-5D était de 0,097 avant la chirurgie et de 0,592 après $(\mathrm{p}=0,0000003)$. Toutes les valeurs de p ont été obtenues au moyen du test de la somme des rangs de Wilcoxon. Conclusion: La vertébroplastie est une intervention sûre et efficace qui procure une amélioration de la douleur et de la qualité de vie.

Can. J. Neurol. Sci. 2005; 32: 487-495

Incidence of osteoporotic compression fractures of the spine is on the rise with the overall increase in the aging population. It is estimated that $18 \%$ of women over 50 and $27 \%$ of men and women over 65 years will develop vertebral fractures in their lifetime. Most of these fractures heal with two-three months of conservative therapy but a minority continue to be painful requiring the use of narcotics and causing restricted mobility, decreased functional capacity and altered psychological state. ${ }^{1}$ This leads to hospitalization and a drain on the social economics of society. ${ }^{2}$ Percutaneous Methylmethacrylate (PMMA) Vertebroplasty, pioneered in France by Deramond et $\mathrm{al}^{3}$ in the 1980s and introduced in the United States in $1988,{ }^{4}$ has received significant praise in the literature as an effective analgesic intervention in the treatment of pain secondary to osteoporotic compression fractures (OCF). Vertebroplasty involves the delivery of PMMA cement into a collapsed or compressed vertebral body under fluoroscopic control by a neurosurgeon, orthopedic surgeon or interventional radiologist to provide

From the Department of Surgery, Section of Neurosurgery (KK, JW, AL), Department of Radiology (AV), Regina General Hospital, University of Saskatchewan, Regina, SK, Canada.

RECEIVED JANUARY 27, 2005. ACCEPTED IN FinAl fORM MAY 27, 2005. Reprint requests to: Krishna Kumar, Medical office wing, Regina General Hospital, Regina, SK, Canada S4P 0W5. 
mechanical fortification with resultant pain relief. Although this does not expand the collapsed vertebra, reinforcing the fractured vertebrae does relieve the pain. The efficacy of vertebroplasty in relief of pain has been shown in various publications ${ }^{5-8}$ but a quantitative evaluation describing improvement in functional capacity, quality of life, mental function, reduction in drug intake and impact on hospital admissions have not been fully addressed. The object of this study is to fill this void and also to assess the efficacy and complications in the treatment of osteoporotic compression fractures by vertebroplasty.

In recent years several investigators have tried to expand the role of vertebroplasty beyond the treatment of osteoporotic fractures to include its role in symptomatic neoplastic conditions of the spine, ${ }^{9-11}$ fractures of the pelvis ${ }^{12}$ and hemangiomas of the spine. ${ }^{13-15}$ The use of vertebroplasty in prophylactic treatment to prevent the collapse of a vertebral body which is at risk is under investigation. Such cases might do better with osteoconductive cements or bone morphogenic proteins rather than PMMA cement.

\section{Methods}

\section{Patients}

This is a prospective study of patients who underwent vertebroplasty at our institution over two and a half years. Over this period a total of 42 patients with 83 vertebral fractures were treated, as some patients had multiple fractures (Figure 1). The series includes 28 women and 14 men with a mean age of 74.8 years (range 44-90). Two patients were lost to follow up and one patient died three weeks following vertebroplasty secondary to cardiac problems unrelated to the procedure, leaving a series of 39 active patients with a mean follow up period of 9.1 months (range 3-30 months). Primary indications of vertebroplasty were moderate to severe pain from a radiologically confirmed compression fracture refractory to about three-four weeks of conservative therapy which consisted of bed rest, narcotics and external bracing. It is crucial to assure that the level of the pain corresponds to the level of the fractured vertebrae being treated. All these patients had a major disability marked by an inability to walk beyond their home without the use of a cane or walker and severe limitation in performing activities of daily living. We had preferred to avoid doing vertebroplasty in the acute phase in the first two to three weeks after fracture, as in our experience some of these fractures become asymptomatic due to the natural healing process.

Preoperative work-up consisted of a complete physical examination and diagnostic studies which included x-ray and computed tomogram (CT) scan/magnetic resonance imaging (MRI) of the spine. These studies allow for evaluation of the dominantly painful level and for assessment of less symptomatic fracture at a different level. The CT scan better defines the posterior wall of the vertebral body and is effective in the evaluation of discontinuity of the posterior wall. This finding should alert the surgeon of a higher risk of cement leaking into the spinal canal and possible spinal cord compromise should vertebroplasty be proceeded with. Magnetic resonance imaging (MRI) is preferred over CT scan as it reveals the presence of edema in those vertebral bodies that are recently fractured and responsible for the production of pain. The MRI is also preferred if there is a concern for tumor involvement. Bone scans are performed in problematic or early fractures and to exclude malignancy in the collapsed vertebrae. The CT scan is preferred over MRI in postoperative evaluation of cement leak outside of the vertebral body. In order to evaluate and follow the benefits of vertebroplasty, each patient completed pre and postoperatively a questionnaire consisting of the Visual Analogue Scale (VAS) ${ }^{16,17}$ for pain, the Oswestry Disability Index (ODI), ${ }^{18}$ the Rolland Morris Scale for back pain (RMS) ${ }^{19,20}$ and EQ-5D. These evaluations were repeated at one week, one month, three months and six month intervals thereafter. All the p-value calculations reported in this paper were performed using the Willcoxon sign-ranked test.

\section{VAS}

Patients' pain level was assessed using the VAS of 0-10. Patients were asked to mark on a scale of 0 to 10 , with 0 being no pain and 10 being the most severe pain they had following the fracture.

\section{$O D I$}

The ODI has become one of the principal condition-specific outcome measures used in the management of spinal disorders. ${ }^{18}$ It assesses patients' disability and functional capacity.

\section{$R M S$}

The RMS is a 24 item questionnaire that over the years has been validated extensively in literature as a reliable and sensitive measure of disability related to back pain. ${ }^{19,20}$ It was originally derived from the Sickness Index Profile which is a generic health status measure.

\section{$E Q-5 D$}

The EQ-5D, a generic health related quality of life questionnaire, measures health in five different dimensions, mobility, self care, usual activities, pain/discomfort and anxiety/depression. Each dimension has three levels of severity: no problem (coded as 1), some/moderate problem (coded as 2) and severe/extreme problem (coded as 3 ) so that each health state can be represented by a five digit vector ranging from 11111 (best possible health state) to 33333 (worst possible health state). Thus the health state 22213 represents moderate problems in mobility, self-care and usual activities; no pain; and extreme anxiety and depression. EQ index scores were then deduced from the vectors, with an index score of 1.0 representing the best possible health state. ${ }^{21}$ The Dolan method was utilized in determining EQ index scores. ${ }^{22}$

The follow-up was performed by a third party not associated with the treatment by personal interview or, for patients who were fragile and couldn't attend, by phone or by mail. If the patient could not be contacted by a minimum of three telephone calls or twice by mail the patient was considered as lost to follow-up.

\section{Contraindication}

Contraindications included patients improving with conservative management, uncorrected coagulopathy, osteomyelitis or vertebral body collapse of greater than $80 \%$ as it poses a problem in percutaneous access and cement delivery (Figure 2). The presence of retropulsed fragments causing spinal 
Vertebral hevers Trangtenct

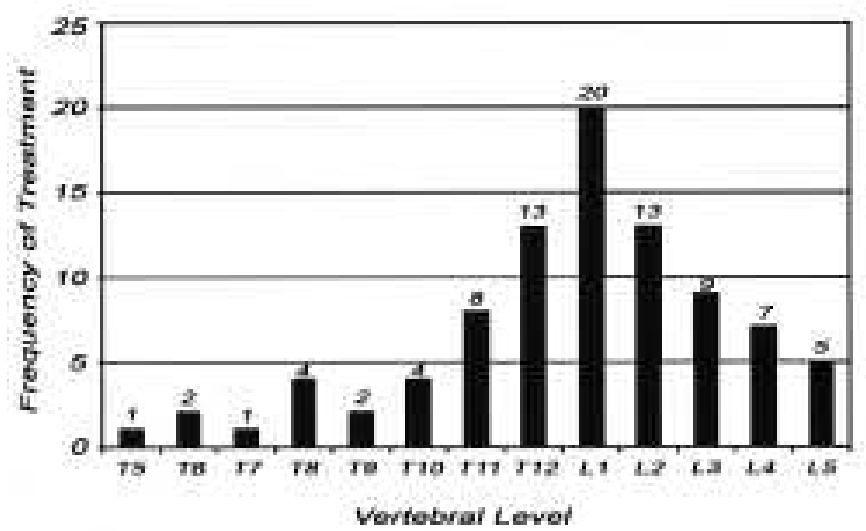

Figure 1: Bar graphs representing the distribution of the osteoporotic compression fractures treated.

canal compromise of greater than $20 \%$ or evidence of tumoral destruction of the posterior wall of the vertebral body with the extension of the tumor into the epidural space, especially in the thoracic region, also contraindicates vertebroplasty. Persistent back pain greater than one year is a relative contraindication as it may suggest that besides the identified compression fractures there are other related mechanical problems present which may continue to generate pain after vertebroplasty.

\section{TeChNiQues}

We employed a technique similar to that described by Jensen et $\mathrm{al}^{8}$ and Mathis et $\mathrm{al}^{23}$ with slight modifications. PMMA vertebroplasty was performed in the neurointerventional angiography suite under biplane fluoroscopic control. This location was preferred over the operating room because here it was possible to generate images of superior quality. The patient was placed in a prone position with the torso well padded. The procedure was performed under conscious sedation using a combination of intravenous administration of fentanyl (Abbot Laboratories North Chicago, IL) for analgesia and midazolam (Roche, Manate, Puerto Rico) for sedation and amnesia, supplemented by local anesthesia. During the procedure blood pressure, electrocardiographic readings and oxygen saturation were continuously monitored. We prefer to use intravenous prophylactic antibiotic (cefazolim, 1 gram) as an alternative to adding antibiotic (tobramycin) in the cement mixture as practiced in some centers. The pedicles of the involved vertebrae were identified fluoroscopically and the overlying skin marked with an ink pen. The back was prepared and draped. The skin and the periosteum overlying the pedicle was then infiltrated with $1 \%$ xylocaine. A small stab incision was made in the skin and an 11 gauge vertebroplasty needle (Stryker Canada) was advanced under fluoroscopic control through the pedicle into the vertebral body and the tip was positioned at the junction between the anterior and middle third of the vertebral body. We used a bipedicular approach in 61 vertebral fractures and a unilateral approach in 22 fractures. In this series we did not use the

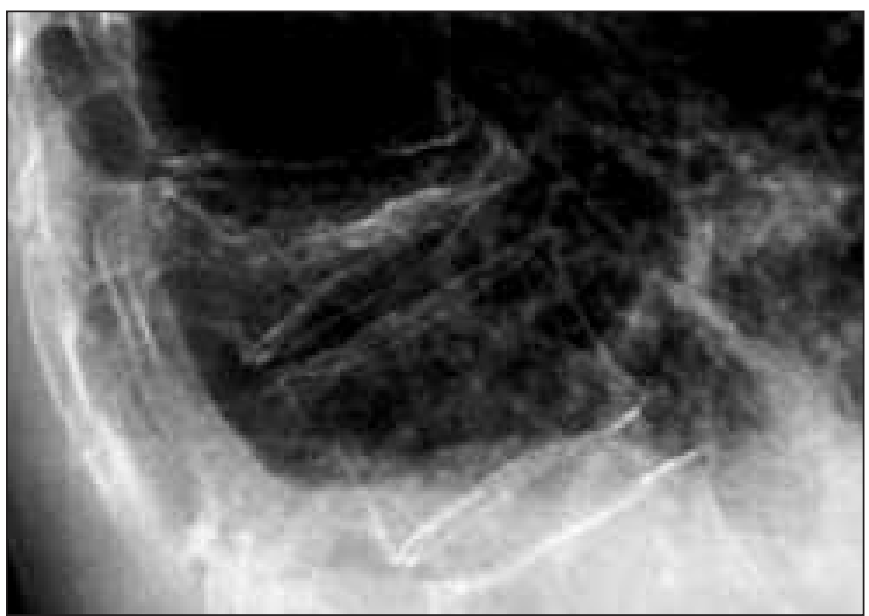

Figure 2: Lateral view of the dorsal spine showing 80-90\% compression fracture especially of the anterior aspect of the vertebral body. Such extreme fractures are not suitable for vertebroplasty.

paraspinal approach. Intraosseous venography was not performed as a routine unless excessive blood oozing was noticed after the needle was in place and the stylet was removed. Intraosseous venography identified only one case of a large venous drainage which could not be occluded by injection of gelform/avitene. This resulted in the termination of the procedure without doing vertebroplasty (Figure 3).

The compression fractures were treated by an injection of a mixture which consisted of 40g of PMMA cement (Simplex P;Stryker-Howmedica-Osteonics, Rutherford, NJ) to which barium sulfate ( $30 \%$ by wt/vol) was added. The addition of this extra amount of barium was to increase the opacity of the mixture so that it could be closely followed during delivery and

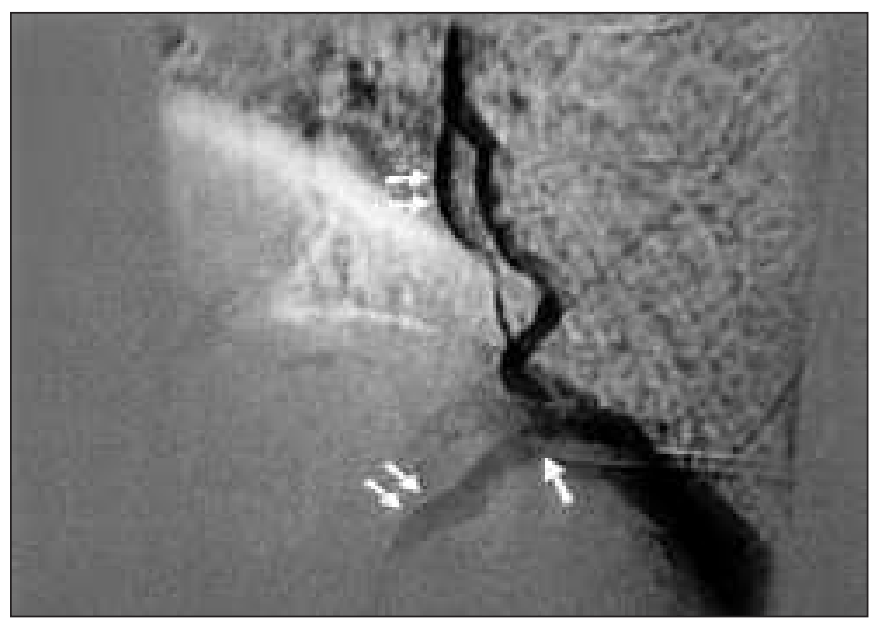

Figure 3: Intraoperative intraosseous venogram (lateral view) showing the excessive filling of large paraspinal veins which could not be obliterated by injection of gelform/avitene. This forced cancellation of vertebroplasty. In such a case if PMMA is injected it could lead to pulmonary embolism. Single arrow points to the needle tip in the vertebral body and double arrows point to the large draining veins. 
for easy identification of any extravasation. During the cement deposition continuous fluoroscopic checks were made to assure that the cement stayed within the vertebral body without migrating into the spinal canal, venous plexus or along the nerve roots. The volume of cement mixture injected ranged from 2.5 to $12 \mathrm{cc}$ per vertebrae. Following the procedure, patients were observed in the recovery room for about six hours before being discharged home. An occasional patient who lived alone and couldn't look after him or herself required overnight admission. In our series four elderly patients who lived alone had to be admitted for an over-night stay. One patient had to be admitted for a two night stay as he complained of postoperative chest pain and had to be investigated to rule out angina.

\section{RESUlts}

In this series there were 39 active patients with a mean follow-up of 9.1 months. There was marked pain improvement in 34 patients $(87 \%)$. The VAS score improved from a mean preoperative score of 8.2 to a mean postoperative score of 2.9 $(\mathrm{p}<0.001)$ at one week follow up and a mean postoperative score of $3.9(\mathrm{p}<0.001)$ at the last follow-up indicating that the improvement seems to persist. The slight increase in VAS score at a longer follow-up period may be a reflection of increased activity of the patients. Two patients experienced no change in their pain status and one experienced increased pain. The RMS showed a drop from a mean preoperative rating of 13 to a mean rating of 10 at last follow-up, showing a $25 \%$ improvement in patients disability following vertebroplasty $(\mathrm{p}=0.0207$ Willcoxin sign-ranked test). The Oswestry Disability Index preoperatively was 64.4 which improved to 43.8 at last follow-up, showing a $32 \%$ improvement ( $\mathrm{p}=0.0207$ Willcoxin sign-ranked test).

The EQ-5D showed a mean preoperative index value of 0.097 and index value of $0.592(\mathrm{p}=0.0000003$, Willcoxin sign-ranked test) at last follow-up. The improvement in EQ-5D postoperatively indicates an overall improvement in health related quality of life. Prior to the vertebroplasty 33 patients were identified as moderately to severely depressed or anxious, postoperatively only 19 patients belonged to this category. Before vertebroplasty 35 patients in this series were moderately to severely limited in their mobility and 25 were moderately to severely limited in performing self-care. By last follow up after vertebroplasty, these values changed to 23 and 19 respectively. Each of the five dimensions (mobility, self-care, usual activities, pain/discomfort and anxiety/depression) measured by EQ-5D showed significant improvement $(\mathrm{p}<0.01$, Willcoxin sign-ranked test) at last follow-up (Figure 4).

Nineteen patients required orthotic bracing to help in their pain management and mobility preoperatively. Postoperatively, within the first two-three weeks, nine patients were able to discard their bracing (47\% reduction). At three months followup, 12 had discontinued the use of their brace (63\% reduction). At last follow-up, seven patients preferred to continue to use the brace intermittently even though they found that their pain secondary to the osteoporotic fracture had improved considerably.

Preoperatively 14 patients required assistance from family members in managing tasks of daily living. On detailed questioning it appeared that eight of them had been requiring this assistance for six months or more prior to the onset of the osteoporotic fracture. The other six who started to need help after the onset of their fracture were able to discontinue this help postoperatively.

Twenty-three of the $39(59 \%)$ active patients were able to decrease their narcotic administration by $50 \%$ within the first month postoperatively. The others continued to use some nonnarcotic analgesics to control the pain originating from other sources especially hip or knee disease. These patients preoperatively were also utilizing adjunctive therapies like physiotherapy, chiropractic adjustments, acupuncture and massage therapy. All were able to discontinue these therapies postoperatively.

Hospital admissions for osteoporotic fractures were quite frequent prior to the introduction of vertebroplasty at our institution. In the year preceding this study 18 patients required hospital admission for a mean average of 13 days. In this series, only one patient had to be admitted to the hospital as a result of complication of the cement leaking into the spinal canal causing weakness in the legs and required decompressive laminectomy and was hospitalized for two weeks.

\section{Complications}

The complications in this series were limited to the leakage of cement beyond the confines of the vertebral body being injected. Leakage was observed in 18 out of 83 vertebral fractures treated (22\%). In seven instances leakage occurred into the intervertebral disc space, in four cement leaked anteriorly through cracks in the ventral surface of the vertebral body, and in four cement leakage was noted laterally along the nerve root (Figure 5). However, only one patient complained of transitory radicular pain which improved within a week without surgical intervention. In three instances cement leakage was noted

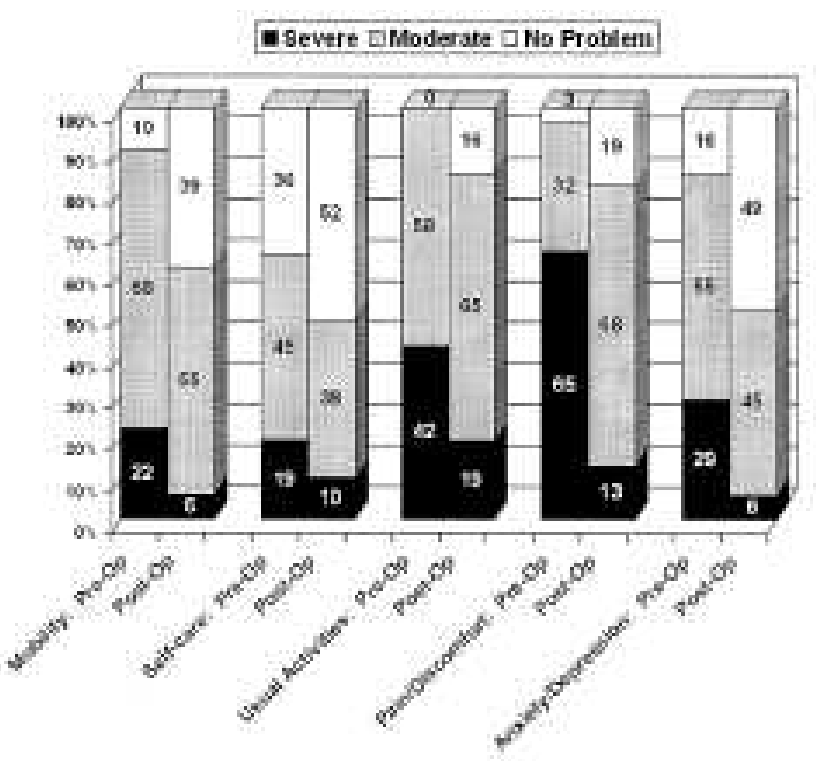

Figure 4: Bar graphs showing the pre and postoperative results for five dimensions measured by $E Q-5 D$. 


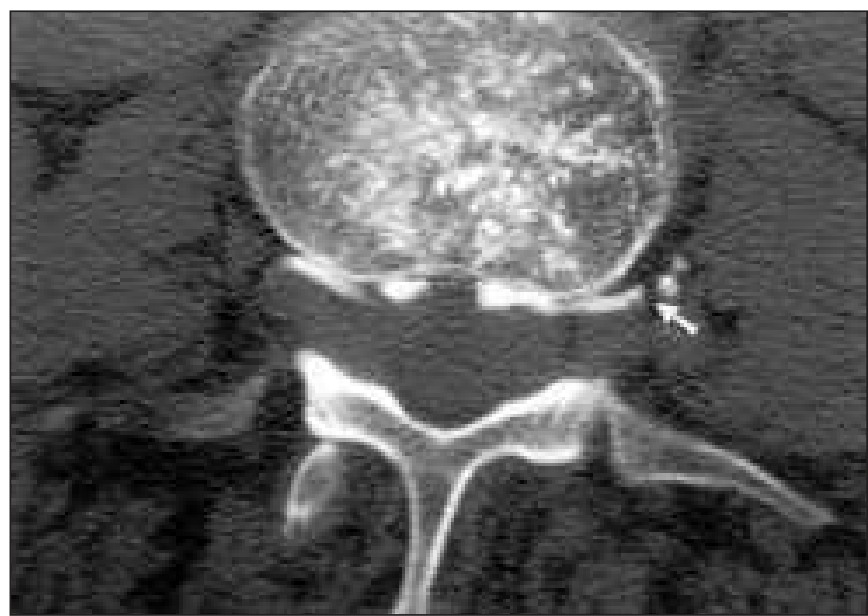

Figure 5: Axial CT scan showing a nonsymptomatic extravasation of PMMA along the nerve roots.

posteriorly in the epidural space, possibly through cracks in the posterior wall of the vertebral body or filling epidural veins. This phenomenon does not progress to neurological deficit provided that injection of the cement is stopped at this stage. This is best confirmed postoperatively with axial CT (Figure 6). In two cases this encroachment was less than $5 \%$ of the spinal canal and did not cause any sign of cord compression, irritation or need for any surgical intervention. But, in the third case the patient developed a paraparesis at the conclusion of the injection and the subsequent CT scan and MRI confirmed that cement occupied $30-40 \%$ of the epidural space (Figure 7). This patient improved considerably in the next few hours but as the weakness in the hip flexors and the quadriceps persisted, anterolateral decompression and removal of the cement was required a day later. At the last follow-up (one year following surgery) this patient is fully ambulatory with a power of $4 / 5$ in hip flexors and full recovery in quadriceps muscles. In this series we had no complication of pulmonary embolism due to cement. One patient became disoriented and restless at the start of the procedure requiring the procedure to be temporarily delayed. In retrospect it appears the confusion and wheezing were caused by the patient lying on his potbelly, pre-existing emphysema and the narcotics administered for neuroepileptic analgesia. There were no fractures of the ribs, sternum or pneumothorax in this series. There were no deaths or infections attributable to the vertebroplasty. We have only two cases of new vertebral fracture adjacent to the treated vertebral segment. This may be a reflection of the limited size of our series.

\section{DisCUSSION}

A Canadian multicentre osteoporosis study ${ }^{24}$ reported on the prevalence of vertebral deformity in Canada in people over 50 years of age. To define the limit of normality, they plotted a normal distribution, including mean and standard deviations (SDs) derived from a reference population without any deformity. They reported a prevalence rate of $23.5 \%$ in women and a rate of $21.5 \%$ in men, using 3 SDs from the mean as the

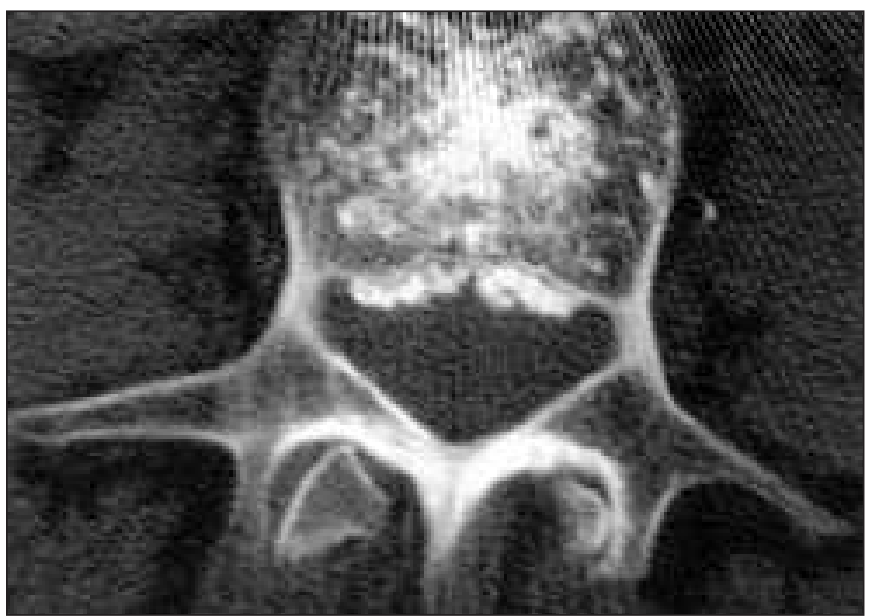

Figure 6: Axial CT scan showing opacification of the ventral epidural veins. This suggests that further injection of cement should be halted.

limit of normality. When they used 4 SDs, the prevalence was $9.3 \%$ and $7.3 \%$, respectivley. They also found the prevalence of vertebral deformity increased with age. For people older than 80 years-of-age, the prevalence for women and men was $45 \%$ and $36 \%$, respectively, using $3 \mathrm{SD}$ as the limit of normality. It is estimated that in Canada at least one in four women older than 50 years will have one or more osteoporosis-related fractures in their lifetimes. The consequences of these fractures are considerable. The vertebral fractures result in pain, lack of mobility leading to respiratory complications, increased kyphosis and in some cases urinary retention requiring increased medical attention and hospitalization. Thus the economic burden to society is substantial with total direct costs (hospitals and nursing homes) in Canada stemming from osteoporosis and associated fractures estimated to be $\$ 1.3$ billion per year. ${ }^{25}$

In the United States, ten million individuals currently suffer from osteoporosis. This results in more than 1.5 million fractures annually, with the vertebral fractures amounting to 700,000 $(47 \%)^{12,26,27}$ and estimated national expenditures (hospital and nursing homes) for osteoporosis and associated fractures estimated at $\$ 17$ billion in 2001 and climbing (Statistics from National Osteoporosis Foundation, Washington D.C., 2004).

The estimated lifetime risk of developing a spine, hip or wrist fracture after the age of 50 years is $40 \%$ in women and $13 \%$ in men, with vertebral (spine) fractures as the most common type of osteoporotic fracture. ${ }^{28}$ Until the advent of minimally invasive procedures like vertebroplasty or recently kyphyoplasty, the treatement of OCFs was either medical or open surgery. In cases without neurological involvement the medical treatment consisted of bed-rest, orthotic management and analgesics. However these treatments are not free of side effects. Bed rest over time results in bone and muscle loss, development of chronic pain, deterioration of underlying medical conditions in this elderly population and incomplete healing of the vertebral fracture with progressive collapse of the vertebral body causing kyphosis. Medications invariably lead to altered mood or mental status. Surgery in these patients has limited indication due to its inherent risks and invasiveness in patients with poor quality 
osteoporotic bones. The surgical treatment is limited to patients with neurological deficits.

The treatment by vertebroplasty in OCFs has shown enormous promise as it rapidly eliminates the pain of the fracture and improves quality of life while the medical treatment of osteoporosis continues. The procedure being minimally invasive, can be performed on an outpatient basis with low morbidity and mortality. With increased experience with the procedure, the risk of cement leakage causing major complication like paraparesis, nerve root compression or pulmonary embolism is declining. In our series marked or complete relief of pain was noted in 34 patients $(87 \%)$. The VAS score improved from a mean preoperative score of 8.2 to a mean postoperative score of 2.9 at one week follow-up and a mean postoperative score of 3.9 at the last follow-up indicating that the improvement is lasting. In our series we had only one case of cement leaking in the spinal canal (occurring during the early phase study) requiring decompressive surgery and leading to subsequent recovery. We had no cases of pulmonary embolisms or death. Similar improvements have been recorded in the literature. ${ }^{1,5-8}$

We have preferred to do vertebroplasty in the subacute phase of the fracture allowing about three weeks for natural healing to take place and for pain to start subsiding. This excludes the need to submit every case of OCF to vertebroplasty. In the literature, ${ }^{29,30}$ leakage of cement into the intervertebral or paravertebral space has been reported in $30-70 \%$ of the vertebroplasties performed at various stages (in the acute or subacute stages). ${ }^{29}$ In our series where we have opted to perform vertebroplasty in the subacute phase, the cement leakage has been $22 \%$, formulating our impression that the results are superior when the procedure is performed in the subacute phase. This is supported by the recent work of Shang-Won Yu et al ${ }^{31}$ who reported the complication rate of cement leakage is much higher when vertebroplasty is performed in the acute phase (first two weeks following the fracture) $27.3 \%$ as compared to $4.5 \%$ in the subacute phase (two to eight weeks following the fracture). The pain relief is also lower ( 24 hours after injection): $72.7 \%$ when vertebroplasty is performed in the acute phase compared to $90.9 \%$ when it is performed in the subacute phase..$^{31}$

Although pain relief following vertebroplasty has been corroborated extensively, the exact mechanism that underlies the reduction in pain remains uncertain. It is postulated that the exothermic reaction that occurs when the PMMA polymerizes generates enough heat to destroy nocioceptive receptors within the vertebrae ${ }^{32,33}$ thus relieving the pain. Another likely explanation is that PMMA fortifies the collapsed vertebral body and thereby prevents painful micromotion. ${ }^{34,35}$ In ex-vivo studies, injection of cement into the vertebral body nearly restores the stiffness and increases the strength. ${ }^{34,36-38}$ This is the most likely mechanism of how vertebroplasty relieves pain as cadaveric studies also confirm that compressed vertebral bodies after PMMA cement injection had significantly increased strength and load bearing capacity compared with intact vertebral bodies. ${ }^{34,37,38}$

Outcomes of vertebroplasty are inherently subjective and placebo effect cannot be totally excluded. Most of the studies have not specifically evaluated functional dimensions and those who have attempted to do so, have done so by utilizing limited parameters. Zoarski et $\mathrm{al}^{6}$ reported an improvement in SF-36 $(\mathrm{p}=0.0004)$. Amar et $\mathrm{al},{ }^{26}$ in a retrospective analysis on 97 patients, reported that $74 \%$ of them experienced an improvement in their quality of life as measured by ambulation, sleep comfort and reduction in analgesic use.

In cancer patients, on the other hand, Fourney et $\mathrm{al}^{9}$ examined the efficacy of vertebroplasty and found a subjective improvement in ambulatory capacity, without improvement in functional capacity measured by Frankel grades.

In order to eliminate some of this bias and place emphasis on quality of life improvements we have added ODI, RMS and EQ$5 \mathrm{D}$ to the VAS to objectively measure the quality of life improvement. These surveys were administered to the patient to assess the improvement in quality of life and functional status following vertebroplasty.

Our study shows a statistical improvement in functional status and decrease in disability. Improvements in RMS $(\mathrm{p}=0.0207)$ and ODI $(p=0.0207)$ postoperatively are confirmatory. Our analyses of EQ-5D reveal an overall improvement in healthrelated quality of life and show statistically significant improvement in mobility, self care, usual activities, pain/discomfort and mood/anxiety $(\mathrm{p}<0.01)$. A sub analysis of our results also showed a reduction in narcotic/analgesic administration, bracing, hospital admissions, adjunctive therapies and home care.

In our series we have used both uni and bipedicular approaches. The bipedicular approach was utilized as a routine. The unipedicular approach was used in cases where the degree of compression fracture was about $70 \%$ and the operator was able to place the vertebroplasty needle up to the midline as seen in the antero-posterior (AP) projection. In these cases we found that a satisfactory filling could be achieved by using the unipedicular approach. The pain relief in such cases was similar to that experienced when the bipedicular approach was used. Tohmeh et $\mathrm{al}^{36}$ has shown that unipedicular approach is equally efficacious. We did not attempt the paraspinal approach as we have been able to perform vertebroplasty using a transpedicular approach in all of our cases and the literature suggests increased risk of injury to viscera. ${ }^{39}$ The risk of cement leakage from the vertebral body along the needle tract is also more likely. ${ }^{23}$

The amount of cement injected does not appear to have a linear correlation with the pain relief or restoration of strength of the collapsed vertebrae. Cotten et $\mathrm{al}^{11}$ in their statistical analysis also showed there is no statistical relationship between the percentage of the vertebrae filling and pain relief. Ex vivo studies fail to show a correlation between the strengthening effects of vertebroplasty and the volume of PMMA injected. ${ }^{34}$

The number of complications causing symptoms following vertebroplasty have been found to be uniformly low in the range of one-three percent. $6,7,9,14$ The most common complication being extravasation of PMMA outside the vertebral body, with rates as high as $73 \%{ }^{1,11,13,40}$ However cement leakage does not always result in neurological deficits or symptomatology. The leakage may take place into the intervertebral disc space, along the nerve root, the epidural space or into the paraspinal veins. Leakage into the disc space, the most common site of leakage in our series, was asymptomatic. Leakage along the nerve root caused temporary radiculopathy in one case which resolved spontaneously. In the literature, radiculopathy due to cement leakage along the nerve root appears to resolve spontaneously 
with conservative measures. ${ }^{10,26}$ In our series, in one patient cement extravasation caused compromise of $30-40 \%$ of the epidural space requiring surgical intervention. This happened early in our series. In this case the vertebral body was so soft that the operator injected up to $12 \mathrm{cc}$ of cement and the fluoroscopy was done only intermittently. Since then we have changed the protocol to use a continuous fluoroscopy during injection and not to attempt to vigorously fill the vertebral body. After implementing these precautions we had no significant leak into the epidural space that required surgical intervention. Minor filling of the epidural space, less than 5\%, is usually asymptomatic. Similarly, streaks of PMMA along the beginning of the paraspinal veins are asymptomatic as the cement is quite viscous and solidifies rapidly thus inhibiting propagation of the cement into larger veins and preventing pulmonary embolism (Figure 8). There was no case of pulmonary embolism as a result of this procedure in our series. Fatal cases of pulmonary embolisms from the bone cement have been reported in the literature. ${ }^{41}$ Insufficient polymerization of the cement at the time of injection or the presence of large draining paravertebral veins seen on venography predisposes to this complication. It is suggested that obliterating these rapidly filling paravertebral veins by injecting a slurry of Avitene (Davol Inc, Cranston, RI) tends to abolish this complication. ${ }^{26}$

In our series we had no case of pedicle, rib or sternum fracture

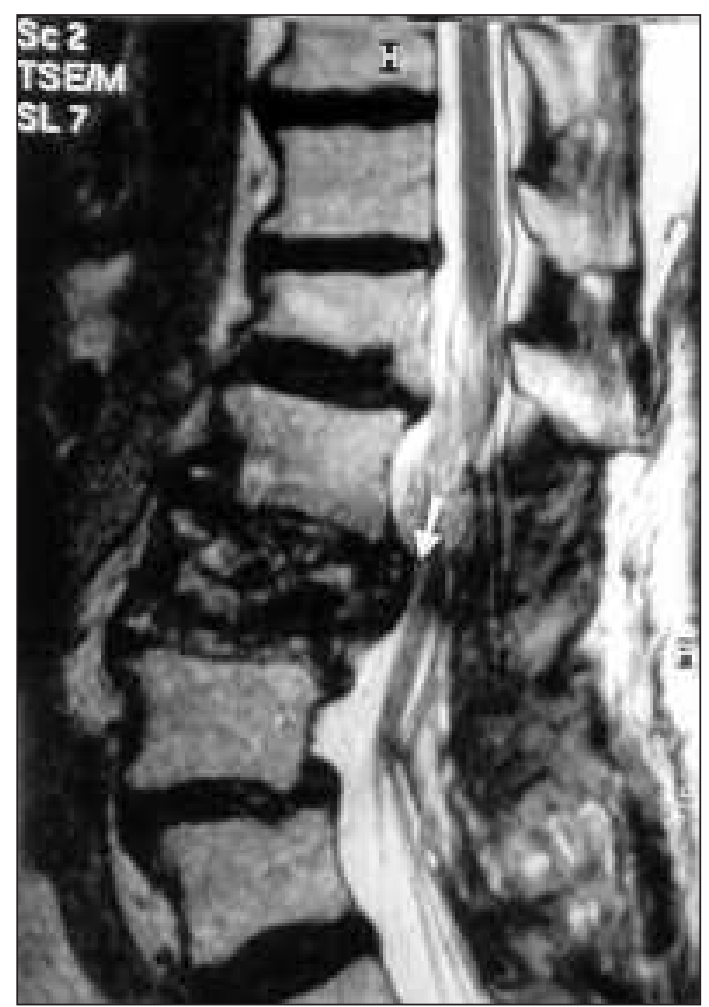

Figure 7: Saggital T2 weighted MRI shows increased retropulsion of the fractured vertebral fragment causing cord compression following vertebroplasty. This case required anterolateral decompressive removal of the cement along with the retropulsed bone fragment.

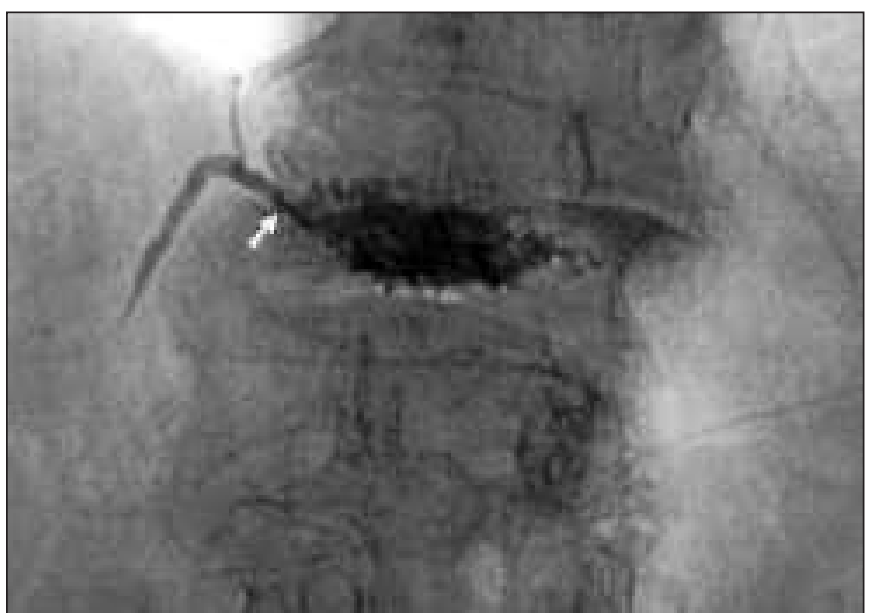

Figure 8: AP view of the dorsal lumbar spine. At L1 the cement opacifies the small paraspinal vein for a short distance. These are asymptomatic.

although these have been reported in the literature. We had a much lower rate of major complication which may be related to the fact that at one sitting we limited the vertebroplasty to two segments only.

Kyphoplasty, a modified version of vertebroplasty, has been used in the United States since its FDA approval in 1998. It has been used since 2000 in Europe after receiving approval from CE (Conformite European) and since 2004 in Canada.

The technique of balloon kyphoplasty has been standardized. ${ }^{42,43}$ It is performed with the patient in prone position and under biplanar fluoroscopy guidance. While some centres perform this procedure under general anesthesia, others do under conscious sedation (including our centre). In brief it consists of inserting an 11-gauge Jamshidi needle into the fractured vertebral body on either side using a transpedicular approach and advanced through the pedicles until reaching the posterior one third of the vertebral body. Through these cannula, inflatable bone temp balloons are placed in the vertebral body and inflated with a standard balloon-plasty technique. This not only creates a focal cavity to fill with cement, but also attempts to re-expand the vertebral body and thus restore height. A PMMA preparation is than used to fill the void left by the balloon. The PMMA used in kyphoplasty is more viscous and is injected under lower pressure as compared to vertebroplasty. We started doing this procedure since the beginning of this year and have gained limited experience.

The pain relief produced by kyphoplasty is equivalent to that achieved by vertebroplasty, both in our experience and as quoted in the literature. ${ }^{42-44}$ Restoring the height of the fractured vertebral body is not possible by vertebroplasty. However with kyphoplasty total height restoration is not always complete. In one study, the absolute mean height gain was $2.9 \mathrm{~mm} .{ }^{45}$ There have been no cases of pulmonary embolism reported in the literature. The extravertebral cement leakage following kyphoplasty appears to be lower $(9.8 \%) .{ }^{46}$ This may be secondary to the cavity created by the bone temp balloon. There are two cases reported by Garfin et $\mathrm{al}^{42}$ of spinal cord injury 
following kyphoplasty. In one case it was due to the malplacement of the cannula, resulting in cement leakage in the spinal canal. In the other, the patient had a fracture at the junction of the body and pedicle and an anterior cord syndrome developed following performance of kyphoplasty through an inferior extrapedicular approach.

The disadvantage of kyphoplasty is the higher learning curve, increased time to perform the procedure and higher cost. The expected total direct medical cost per patient is about $\$ 700$ for standard vertebroplasty and $\$ 4,300$ for balloon kyphoplasty. ${ }^{47}$

There are currently no controlled randomized trials to prove the superiority of one procedure over the other.

The frequency of osteoporotic fractures are on the rise secondary to the increase in the aging population and improved length of survival. This poses an enormous public health problem. Percutaneous vetebroplasty is a safe and effective procedure in the treatment of OCFs that are refractory to conservative therapy. The best results are achieved when vertebroplasty is performed in a subacute stage with fewer complications. In this study we have shown improvements in pain, increased mobility, functional capacity and quality of life following vertebroplasty. The performance of vertebroplasty does require some technical learning and experience. Preoperative MRI is very useful in determining which segments are painful and bipedicular approach is preferred where possible. Future development of bioactive cement or other osteoconductive materials which integrate with the host bone and participate in remodeling of the fractured vertebrae will tend to maximize the functional improvement in ambulation in these cases.

Both vertebroplasty and kyphoplasty are equal in achieving pain reduction, but further controlled randomized trials are needed to validate the superiority of one procedure over the other and to evaluate their cost effectiveness against the natural history.

\section{ACKNOWLEDGEMENT}

No funds were received in support of this work. No benefits in any form have been or will be received from a commercial party related directly or indirectly to the subject of this manuscript.

\section{REFERENCES}

1. Cortet B, Cotten A, Boutry N, et al. Percutaneous vertebroplasty in the treatment of osteoportic vertebral compression fractures: an open prospective study. J Rheumatology 1999; 26:2222-2228.

2. Ray NF, Chan JK, Thamer M, Melton J. Medical expenditures for the treatment of osteoporotic fractures in the United States in 1995: Report from the National Osteoporosis Foundation. J Bone Miner Res 1997; 12:24-31.

3. Galibert P, Deramond H, Roast P, LeGars D. Preliminary note on the of treatment of vertebral angioma by percutaneous acrylic vertebroplasty. Neurochirurgie 1987; 33:166-168.

4. Bascooulergue Y, Duquessnel J, Leclercq R. Percutaneous injection of methylmethacrylate in the vertebral body for $t$ treatment of various diseases; percutaneous vertebroplasty. Radiology 1988; 169:372.

5. McGraw JK, Lippert JA, Minkus KD. Prospective Evaluation of Pain Relief in 100 Patients Undergoing Percutaneous Vertebroplasty: Results and Follow-up. J Vasc Interv Radiol 2002; 13:883-886.
6. Zoarski G, Snow P, Olan W. Percutaneous vertebroplasty for osteoporotic compression fractures: Quantitative prospective evaluation of long-term outcomes. J Vasc Interv Radiol 2002; 13:139-148.

7. Barr JD, Barr MS, Lemley TJ, et al. Percutaneous vertebroplasty for pain relief and spinal stabilization. Spine 2000; 25:923-928.

8. Jensen ME, Evans AJ, Mathis JM, et al. Percutaneous polymethylmethacrylate vertebroplasty in the treatment of osteoportic vertebral body compression fractures: technical aspects. Am J Neuroradiol 1997;18(10)1897-1904.

9. Fourney DR, Schomer DF, Nader R. Percutaneous vertebroplasty and kyphoplasty for painful vertebral body fractures in cancer patients. J. Neurosurg 2003: 98(1 suppl):21-30.

10. Weill A, Chiras J, Simon J. Spinal metastases: Indications for and results of percutaneous injection of acrylic surgical cement. Radiology 199:241-247.

11. Cotten A, Dewatre, Cortet B, et all: Percutaneous vertebroplasty for osteolytic metastases and myeloma: effects of the percentage of lesion filling and the leakage of methyl methacrylate at clinical follow-up. Radiology 1996; 200:525-530.

12. Mathis JM, Barr JD, Belkoff SM, et all. Percutaneous Vertebroplasty: A developing standard of care for vertebral compression fractures. AJNR Am J Neuroradiol 2001; 22:373381.

13. Cyteval C, Sarraberre MP, Roux JO, et all. Acute osteoporotic vertebral collapse: Open study on percutaneous injection of acrylic surgical cement in 20 patients. AJR Am J Roentgenol 1999; 173:1685-1690.

14. Dousset V, Mousselard H, de Monck d'User L, et al. Asymptomatic haemangioma treated by percutaneous vertebroplasty. Neuroradiology 1996; 38:392-394.

15. Feydy A, Cognard C, Miaux Y, et al. Acrylic vertebroplasty in symptomatic cervical vertebral hemangionmas: Report of 2 cases. Neuroradiology 1996; 38:389-391.

16. Carlsson AM. Assessment of chronic pain: aspects of reliability and validity of visual analogue scale. Pain 1983; 16:87-101.

17. Huskisson EC. Visual analogue scales. In: Melzack R, (Ed.) Pain measurement and assessment. New York: Raven Press, 1983: 3340.

18. Fairbank JC, Pynsent PB. The oswestry disability index. Spine 2000; 25:2940-2952.

19. Stratford PW, Binkley JM, Riddle DL. Development and initial validation of the back pain functional scale. Spine 2000; 25:20952102.

20. Jacob T, Baras M, Zeev A, Epstein L. Low back pain: reliability of a set of pain measurement tools. Arch Phys Med Rehabil 2001;82:735-742.

21. Badia X, Montserrat R, Baro E, et al. Impact of IBS Patters on Health Related Quality of Life. http://www.euroqol.org/ meetings/meeting2001/meeting201-16.pdf

22. Dolan P. Modeling Valuations for EuroQol Health States. Medical Care 1997; 35:1095-1108.

23. Mathis JM, Barr JD, Belkoff SM, et al. Percutaneous Vertebroplasty: A developing standard in of care for vertebral compression fractures. AJNR 2001; 22:373-381.

24. Jackson S, Tenenhouse A, Robertson L. Vertebral fracture definition from population-based data: preliminary results from the Canadian Multicenter Osteoporosis Study (CaMos). Osteoporos Int 2000; 11:680-687.

25. Lorrain J, Paiement G, Chevrier N, et al. Population demographics and socioeconomic impact of osteoprotic fractures in Canada. Menopause 2003; 10:228-234.

26. Amar AP, Larsen DW, Esnaashari N, et al. Percutaneous transpedicular polymethylmethacrylate vertebroplasty for the treatment of spinal compression fractures. Neurosurgery 2001; 49: $1105-1115$.

27. Riggs BL and Melton LJ: The worldwide problem of osteoporosis: insights afforded by epidemiology. Bone 1999; 17:505S-511S. 
28. Papaioannou A, Watts $\mathrm{N}$ et al. Diagnosis and management of vertebral fractures in elderly adults. Am J Med 2002; 113: 220228.

29. Rao R, Singrakhia M. Painful Osteoporotic vertebral fracture: pathogenesis, evaluation, and roles of vertebroplasty and kyphoplasty in its management. J Bone Joint Surg Am 2003; 85:2010-2022.

30. Peters K, Guiot B, Martin P, et al. Vertebroplasty for osteoporotic compression fractures: Current practice and evolving techniques. Neurosurgery 2002; 51(suppl 2):96-103.

31. Shang-won Yu, Po-Cheng Lee, Ching-Hou Ma, et al. Vertebroplasty for the treatment of osteoporotic compression spinal fracture: Comparison of remedial action at different stages of injury. J Trauma 2004; 56:629-632.

32. Bai B, Jazrawi LM, Kummer FJ, et al. The use of an injectable, biodegradable calcium ohosphate bone substitute for the prophylactic augmentation of osteoportic vertebrae and the management of vertebral compression fractures. Spine 1999; 24: 1521-1526.

33. Deramond H, Wright NT, Belkoff SM. Temperature elevation caused by bone cement polymerization during vertebroplasty. Bone 1999; 25(suppl 2):17S-21S.

34. Dean JR, Ison KT, Gishen P. The strengthening effects of percutaneous vertebroplasty. Clin Radiol 2000; 55:471-476.

35. Maynard AS, Jensen ME, Schweickert PA, et al. Value of Bone Scan imaging in predicting pain relief from percutaneous vertebroplasty in osteoporotic vertebral fractures. AJNR 2000; 21: 1807-1812.

36. Tohmeh Ag, Mathis JM, Fenton DC, et all. Biomechanical efficacy of unipedicular versus bipedicular vertebroplasty for the management of osteoporotic compression fractures. Spine 1999; 24: $1772-1776$.
37. Belkoff SM, Maroney M, Fenton DC, et al. An in vitro biomechanical evaluation of bone cements used in percutaneous vertebroplasty. Bone 1999; 25:23S-26S.

38. Belkoff SM, Mathis JM, Erbe EM, et al. Biomechanical evaluation of a new bone cement for use in vertebroplasty. Spine 2000; 25:1061-1064.

39. Orr R. Treatment of osteoporotic vertebral compression fractures with vertebral augmentation: Vertebroplasty and Kyphoplasty. Spine Surgery 2004; 5:27-32.

40. Al-assir I, Perez-Higueras A, Florensa J, et all. Percutaneous vertebroplasty: A special syringe for cement injection. Am J Neuroradiol 2000; 21:159-161.

41. Padovani B, Kasriel O, Brunner P, et al. Pulmonary embolism caused by acrylic cement: A rare complication of percutaneous vertebroplasty. AJNR Am J Neuroradiol 1999; 20:375-377.

42. Garfin S, Yuan H, Reiley M: Kyphoplasty and Vertebroplasty for the treatment of painful osteoporotic compression fractures. Spine 2001; 26:1511-1515

43. Phillips F. Minimally invasive treatments of osteoporotic vertebral compression fractures. Spine 2003; 28:S45-S53.

44. Truumees E. Comparing kyphoplasty and vertebroplasty. Advances in osteoporotic fracture management 2002; 1:114-123.

45. Lieberman I, Dudeney S, Reinhardt M, et al. Initial outcome and efficacy of "kyphoplasty" in the treatment of painful osteoporotic vertebral compression fractures. Spine 2001; 26:1631-1638.

46. Phillips F, Ho E, Campbell-Hupp M, et al. Early radiographic and clinical results of balloon kyphoplasty for the treatment of osteoporotic vertebral compression fractures. Spine 2003; 28:2260-2267.

47. Medical Advisory Secretariat Ministry of Health and Long-Term Care Government of Ontario: Balloon Kyphoplasty: Health Technology Literature review. December 2004. 